\title{
Superior - subordinate request email in workplace communication of a Malaysian organisation
}

\begin{abstract}
Email is key in workplace communication. This study examines structure of request emails and display of politeness by Malaysian superiors when writing to subordinates. Authoritative and solidarity-oriented structures with corresponding linguistic strategies were found to reflect different leadership styles, autocratic and democratic. Language and communicative style were influenced by situational context of a request. When face threat and imposition were low, superiors were authoritative and when face threat and imposition were high, they were egalitarian. Email functioned as an equalising medium that enabled superiors to be democratic as well as a channel for power enactment that reinforced hierarchical structures.
\end{abstract}

Keyword: Request email; Power; Politeness; Leadership; Workplace communication; Pragmatics 